\title{
Recent Stirling Conversion Technology Developments and Operational Measurements at NASA Glenn Research Center
}

Salvatore M. Oriti and Nicholas A. Schifer

Glenn Research Center, Cleveland, Ohio 


\section{NASA STI Program . . . in Profile}

Since its founding, NASA has been dedicated to the advancement of aeronautics and space science. The NASA Scientific and Technical Information (STI) program plays a key part in helping NASA maintain this important role.

The NASA STI Program operates under the auspices of the Agency Chief Information Officer. It collects, organizes, provides for archiving, and disseminates NASA's STI. The NASA STI program provides access to the NASA Aeronautics and Space Database and its public interface, the NASA Technical Reports Server, thus providing one of the largest collections of aeronautical and space science STI in the world. Results are published in both non-NASA channels and by NASA in the NASA STI Report Series, which includes the following report types:

- TECHNICAL PUBLICATION. Reports of completed research or a major significant phase of research that present the results of NASA programs and include extensive data or theoretical analysis. Includes compilations of significant scientific and technical data and information deemed to be of continuing reference value. NASA counterpart of peer-reviewed formal professional papers but has less stringent limitations on manuscript length and extent of graphic presentations.

- TECHNICAL MEMORANDUM. Scientific and technical findings that are preliminary or of specialized interest, e.g., quick release reports, working papers, and bibliographies that contain minimal annotation. Does not contain extensive analysis.

- CONTRACTOR REPORT. Scientific and technical findings by NASA-sponsored contractors and grantees.
- CONFERENCE PUBLICATION. Collected papers from scientific and technical conferences, symposia, seminars, or other meetings sponsored or cosponsored by NASA.

- SPECIAL PUBLICATION. Scientific, technical, or historical information from NASA programs, projects, and missions, often concerned with subjects having substantial public interest.

- TECHNICAL TRANSLATION. Englishlanguage translations of foreign scientific and technical material pertinent to NASA's mission.

Specialized services also include creating custom thesauri, building customized databases, organizing and publishing research results.

For more information about the NASA STI program, see the following:

- Access the NASA STI program home page at http://www.sti.nasa.gov

- E-mail your question via the Internet to help@ sti.nasa.gov

- Fax your question to the NASA STI Help Desk at $443-757-5803$

- Telephone the NASA STI Help Desk at 443-757-5802

- Write to: NASA Center for AeroSpace Information (CASI) 7115 Standard Drive Hanover, MD 21076-1320 


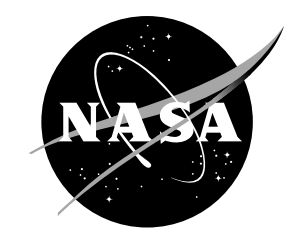

\section{Recent Stirling Conversion Technology Developments and Operational Measurements at NASA Glenn Research Center}

Salvatore M. Oriti and Nicholas A. Schifer

Glenn Research Center, Cleveland, Ohio

Prepared for the

Seventh International Energy Conversion Engineering Conference (IECEC)

sponsored by the American Institute of Aeronautics and Astronautics

Denver, Colorado, August 2-5, 2009

National Aeronautics and

Space Administration

Glenn Research Center

Cleveland, Ohio 44135 


\section{Acknowledgments}

Some work described in this paper was performed for the Science Mission Directorate (SMD) and the Radioisotope Power System (RPS) Program, which provided funding for these projects.

Level of Review: This material has been technically reviewed by technical management.

Available from

NASA Center for Aerospace Information 7115 Standard Drive

Hanover, MD 21076-1320
National Technical Information Service 5301 Shawnee Road Alexandria, VA 22312

Available electronically at http://gltrs.grc.nasa.gov 


\title{
Recent Stirling Conversion Technology Developments and Operational Measurements at NASA Glenn Research Center
}

\author{
Salvatore M. Oriti and Nicholas A. Schifer \\ National Aeronautics and Space Administration \\ Glenn Research Center \\ Cleveland, Ohio 44135
}

\begin{abstract}
In support of the Advanced Stirling Radioisotope Generator (ASRG) project and other potential applications, NASA Glenn Research Center (GRC) has initiated convertor technology development efforts in the areas of acoustic emission, electromagnetic field mitigation, thermoacoustic Stirling conversion, and multiple-cylinder alpha arrangements of Stirling machines. The acoustic emission measurement effort was developed as a health monitoring metric for several Stirling convertors undergoing life testing. While accelerometers have been used in the past to monitor dynamic signature, the acoustic sensors were chosen to monitor cycle events, such gas bearing operation. Several electromagnetic interference (EMI) experiments were performed on a pair of Advanced Stirling Convertors (ASC). These tests demonstrated that a simple bucking coil was capable of reducing the alternating current (ac) magnetic field below the ASRG system specification. The thermoacoustic Stirling concept eliminates the displacer typically found in Stirling machines by making use of the pressure oscillations of a traveling acoustic wave. A $100 \mathrm{~W}$-class thermoacoustic Stirling prototype manufactured by Northrop Grumman Space and Technology was received and tested. Another thermoacoustic prototype designed and fabricated by Sunpower, Inc., will be tested in the near future. A four-cylinder free piston alpha prototype convertor was received from Sunpower, Inc. and has been tested at GRC. This hardware was used as a proof of concept to validate thermodynamic models and demonstrate stable operation of multiple-cylinder free-piston Stirling conversion. This paper will discuss each of these activities and the results they produced.
\end{abstract}

\section{Introduction}

The NASA Glenn Research Center (GRC) has been supporting the joint NASA, Department of Energy (DOE), and Lockheed Martin (LM) development of the Advanced Stirling Radioisotope Generator (ASRG) for several years (Ref. 1). The ASRG design comprises two Advanced Stirling Convertors (ASCs) designed and manufactured by Sunpower, Inc. The use of Stirling power conversion offers a four-fold increase in conversion efficiency when compared to thermoelectric conversion. The ASC began as a technology development contract under a NASA Research Announcement in 2003 (Ref. 2). In 2008, LM successfully completed an engineering unit (EU) generator, with two ASC-Es (engineering) (Ref. 3). The ASRG-EU was subsequently transferred to GRC and began continuous extended operation in late 2008.

In addition to operation of the ASRG-EU, eight other ASC prototypes have been put on extended operation to provide life and reliability data (Refs. 1 and 4). The performance of each convertor is monitored by measurements such as alternator power, current and voltage output, in addition to temperatures, piston position, and thermal energy input. From these data, performance metrics, such as efficiency and West number, can be calculated. Since the aforementioned measurements are external to the convertor (with the exception of piston position), it was desired to augment these with a technique that could reveal information about the internal components. In 2008, an effort was initiated to utilize acoustic emission data to monitor health of the convertors and detect changes in operation. Acoustic sensors were chosen because they can be easily situated on the external surfaces of the convertors. 
Also supporting the ASRG project, an activity was initiated to develop and test methods for mitigating convertor electromagnetic interference (EMI) emissions. For the ASRG flight unit there exists a system specification for the alternating current (ac) magnetic field emissions. Some missions may have specialized instruments that require even lower field emissions. Initial measurements on a pair of ASC $-1 \mathrm{~s}$ suggested further ac magnetic field mitigation would be required to meet the ASRG system specification. Two techniques have been employed to accomplish this. The first is a GRC-developed bucking coil that is positioned around the outer surface of the alternator housing and wired in series with the alternator output. This coil passively taps a portion of the convertor power output to generate a magnetic field that nullifies that emitted by the alternator. The second technique is the implementation of an alternator housing fabricated from magnetic-shielding material. This material has a large magnetic permeability, and when placed around the alternator, it will provide greater magnetic field attenuation than traditional vessel materials.

Small Business Innovative Research (SBIR) contracts have also focused on development of relatively low technology readiness level concepts like thermoacoustic and multiple-cylinder alpha free-piston Stirling arrangements. These concepts offer the potential for further increases in specific power and conversion efficiency over current state of the art designs. These concepts also expand the environments that may utilize Stirling conversion. Most notably, thermoacoustic convertors may prove capable of higher hot-end operating temperatures, making them viable for power generation on Venus. As is true for any technology, research is required during the initial stages so that it may develop to a level sufficient for application. Effort is being put into these two concepts with the intention that they will in the future offer enhanced options to missions requiring power conversion.

The ASC-Es incorporated into the ASRG-EU are of the typical beta style, meaning the piston and displacer share a common axis of motion. Arrangement in the alpha, or multiple-cylinder configuration has been shown to offer potential improvements in specific power and efficiency over the beta arrangement (Ref. 5). Only recently has free-piston technology been demonstrated to operate in the alpha arrangement (Ref. 6). In 2008, a Phase II SBIR contract was completed by Sunpower, Inc. with Global Cooling Manufacturing, Inc. as a subcontractor. This SBIR effort investigated various alpha arrangements of convertors in the $5 \mathrm{~kW}_{\mathrm{e}}$ output range. The effort also produced a four-cylinder free-piston proof of concept convertor in the $100 \mathrm{~W}_{\mathrm{e}}$ output range. This device was subsequently tested at GRC to gather baseline performance data.

Some activity has also focused on the thermoacoustic arrangement of Stirling conversion. Traditional free-piston Stirling machines, such as those described Reference 2, make use of a mechanical displacer to generate the Stirling cycle's pressure wave that drives the piston. The thermoacoustic arrangement eliminates the displacer and instead utilizes a traveling or standing wave to move the working gas between the hot and cold thermal reservoirs. In this configuration, the portion of the machine that converts heat into a pressure wave has no moving parts. This configuration simplifies the design in some ways since moving components in the hot-end are eliminated. The conversion from mechanical to electrical energy is still done by a piston-driven linear alternator, and thus moving parts are present there, but these are exposed to only relatively mild temperatures. In 2006, a Northrop Grumman Space and Technology thermoacoustic Stirling convertor (Ref. 8) was tested at GRC. In 2008, Sunpower, Inc. delivered their version of a thermoacoustic Stirling convertor, developed under a Phase II SBIR contract. A test station is being built at GRC for operation of this unit and is expected to commence in the summer of 2009.

\section{Nomenclature}

ASC Advanced Stirling Convertor

ASC-E Advanced Stirling Convertor, Engineering Unit

ASRG Advanced Stirling Radioisotope Generator

CTPC Component Test Power Convertor 


$\begin{array}{ll}\text { dBpT } & \text { Decibel picoTesla } \\ \text { DOE } & \text { Department of Energy } \\ \text { EMI } & \text { Electromagnetic Interference } \\ \text { EU } & \text { Engineering Unit } \\ \text { GRC } & \text { Glenn Research Center } \\ \text { LM } & \text { Lockheed Martin } \\ \text { pT } & \text { picoTesla } \\ \text { RPS } & \text { Radioisotope Power System } \\ \text { SBIR } & \text { Small Business Innovative Research } \\ \text { TASHE } & \text { Thermoacoustic Stirling Heat Engine }\end{array}$

\section{Acoustic Emission Characterization}

As of publication, GRC is capable of operating $14100 \mathrm{~W}_{\mathrm{e}}$-class Stirling convertors in a continuous unattended mode to gather performance data over a time period of thousands of hours. The purpose of these tests is to record and analyze convertor performance on many units over a sufficiently long period of time to produce life and reliability data for the ASRG project. An in depth description of the test setup and status of extended operation can be found in Reference 4. Several data are recorded to track performance trends, including input and rejection temperatures, power output, alternator power, working gas pressure, and piston amplitude of oscillation. From the measured data performance parameters such as efficiency and West number are calculated. These parameters are then plotted as a function of time to observe performance trends. With the exception of piston motion measurement, all measured parameters are external to the convertor. In 2008 an effort was initiated to develop a method for monitoring internal component status by observing acoustic emissions through the convertor outer surfaces. In mind were events such as changes in gas bearing operation, piston displacer contact, or changes in operation of the displacer planar spring. The goal of this effort was to develop another convertor performance metric based on the signature of acoustic emissions over time. Acoustic sensors were chosen for this purpose because of their high frequency response which is required for detection of sound waves through metals. The sensors chosen in particular operate in the range of 100 to $600 \mathrm{kHz}$. In contrast, accelerometers have been used to track dynamic balance of the test article as a whole near the convertor operating frequency in the $100 \mathrm{~Hz}$ range.

Acoustic emissions characterization focused mainly on the Sunpower, Inc. ASC-0s and ASC-1HSs, but some measurements were taken on Infinia, Corporation TDCs. Plans are in place to begin acoustic characterization of the ASRG-EU. The sensor chosen for this activity was the Micro30S model from Physical Acoustics Corporation which operates in the frequency range of 100 to $600 \mathrm{kHz}$. The sensors were loaded onto the outer surfaces of the convertors by custom-designed clamps that permitted precise control of the clamping force (Fig. 1).

A Yokogawa DL750 Scopecorder was found to be most useful for signal acquisition. This device was capable of accepting and storing the large amount of data generated via sampling the acoustic sensor and piston position sensor signals. Capturing of the acoustic and piston position signals simultaneously permitted investigation of events that were related to piston motion. The signals were sampled at a rate of $1 \mathrm{MHz}$ over a time period of $100 \mathrm{~ms}$, which captured up to ten cycles of convertor operation.

Furthermore, the device was found capable of storing data at this rate for a window up to $100 \mathrm{sec}$, permitting relatively long-term observation of the acoustic information. 


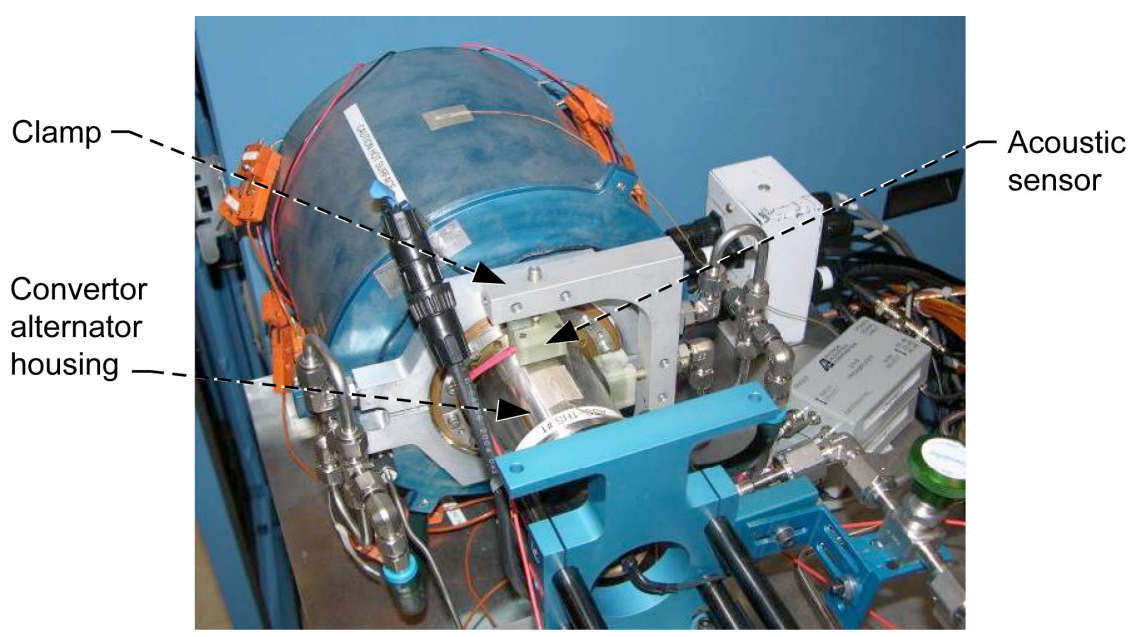

Figure 1.-Acoustic sensor installed on ASC-1HS \#1.

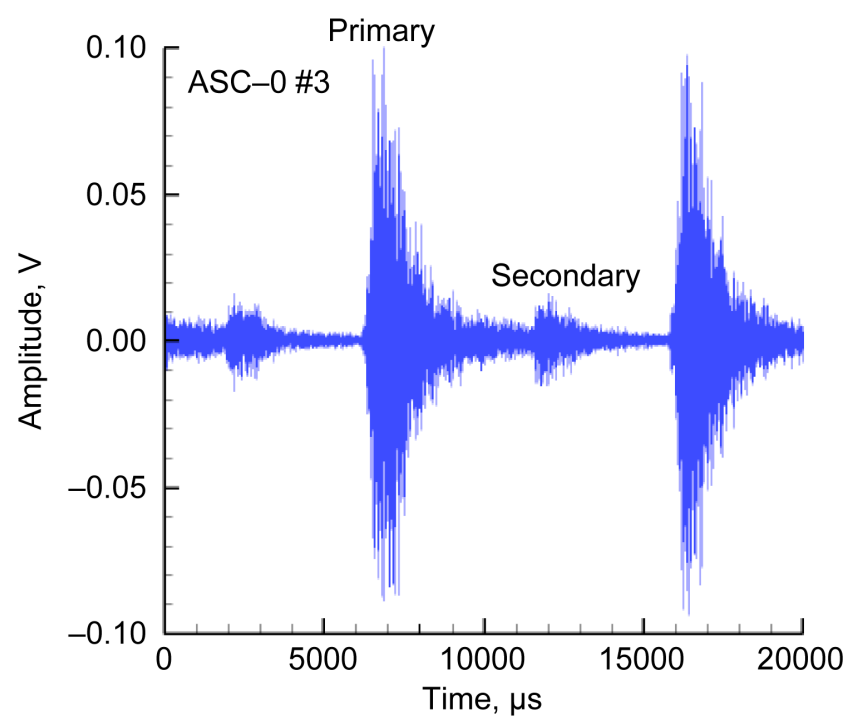

Figure 2.-Typical acoustic signature of ASC-0 \#3 over two piston cycles. The large primary pulse coincides with the midpoint of piston motion toward the hot end, while the smaller secondary pulse lags the primary by $190^{\circ}$.

At the time the acoustic emission characterization activity began, the ASC -0 s \#3 and \#4 and ASC-1HSs \#1 and \#2 were undergoing extended operation, so baseline measurements were first taken on these convertors. The acoustic measurements were then taken on several occasions thereafter on a weekly basis to generate baseline data for trending analysis. The emission spectrum of ASC- 0 \#3 was consistent throughout the observation period. A waveform from the acoustic sensor on ASC -0 \#3 is shown in Figure 2. The signature consists of a primary and secondary pulse. The larger primary pulse coincides with the midpoint of the piston stroke moving towards the hot end of the convertor. The smaller secondary pulse coincides with the midpoint of the stroke in the other direction. The acoustic signatures of the other convertors were similar to that of ASC- $-0 \# 3$, but differences were observed in the nature of the secondary pulses. On ASC- 0 \#4 for example, the timing and amplitude of the secondary pulse did not remain consistent. Rather than lag the primary pulse by $190^{\circ}$, it was observed to lag by various amounts ranging from $66^{\circ}$ to $123^{\circ}$. The amplitude of the secondary pulse from ASC -0 \#4 also varied. On certain occasions it was almost absent, while on others it was as large as the primary. 


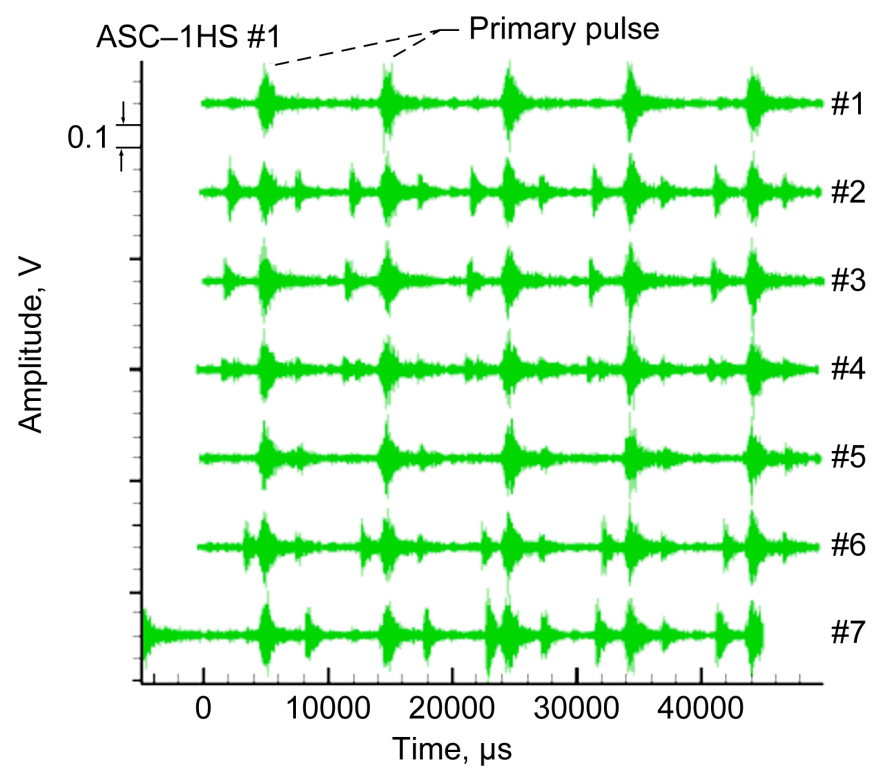

Figure 3.-Various acoustic signatures captured from ASC-1HS \#1 over four piston cycles. The primary pulse is ever-present, while the secondary pulses are transient.

Similar acoustic emission behavior was observed from ASC-1HS \#1 and \#2. Several acoustic sensor waveforms samples from ASC-1HS \#1 are shown in Figure 3. The signature possesses a primary pulse but ASC-1HS \#1 sometimes showed more than one secondary pulse. The arrival and departure of the secondary pulses was a repeatable pattern, and followed the sequence shown in Figure 3. The acoustic emission of ASC-1HS \#2 was consentient and resembled that of ASC-0 \#3.

Few conclusions could be drawn from the activity just described as little was known of the status of the internal components while acoustic signatures were observed. To gather more insight, further testing was performed on a convertor during which the internal components were deliberately disrupted and the effect on acoustic emission observed. These disruptions included disabling of the gas bearings, operating with piston to displacer contact, and loose planar spring fasteners. The intent of this task was to determine if the acoustic emission signature could be used to detect these types of operational changes. While piston to displacer contact and planar spring loosening are catastrophic changes that are not anticipated, slight changes in gas bearing performance could potentially occur, and the ability to detect this offers a useful tool for extended operation analysis.

This testing showed that acoustic signatures were indistinguishable whether or not the gas bearings were functioning. This unfortunately suggested that acoustic emissions were not a viable method for monitoring gas bearing performance. However, the sensors were able to detect piston to displacer contact, as the acoustic emissions were large enough to saturate the sensor. It was found during this investigation that piston to planar spring contact produced a similar effect, and could thus be detected by acoustic sensors (Fig. 4). The acoustic signature during contact is shown in brown, and that of normal, noncontacting operation is shown in yellow. Two of the planar spring fasteners were loosened to observe the effect of a loose planar spring. Similarly, the acoustic emissions were large in this case relative to the case where the spring was properly seated. These tests showed that while the desired insight into gas bearing operation may not be observable with acoustic sensors, other more severe convertor disruptions could be detected. 


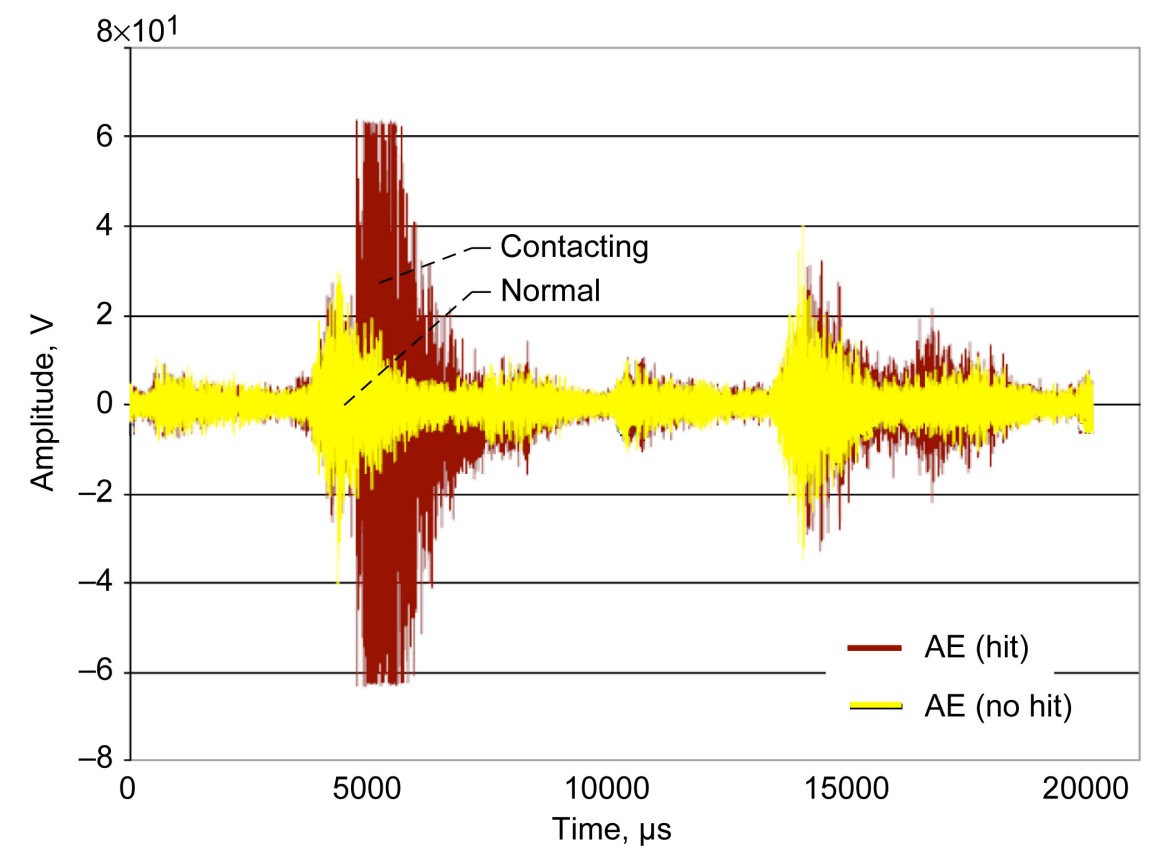

Figure 4.-Acoustic emissions during piston to planar spring contact. The waveform during normal non-contacting operation is shown in yellow. The emissions during contact (brown) were large enough to saturate the sensor.

\section{Electromagnetic Interference Mitigation}

As a power system, the ASRG must meet certain electromagnetic emission requirements so as to not interfere with spacecraft hardware. Not all missions have the same magnetic field emission limits. In particular, those using magnetometers are subject to specifications with significantly lower limits for the ac and dc magnetic field emissions from the power system. Typically, the dc magnetic field is measured in nanoTesla, while the ac magnetic field is measured using the decibel scale. The decibel scale is logarithmic and allows convenient representation of a large range of values that span many orders of magnitude. Expressing a parameter using the decibel scale must be done relative to some value. In the case of ac magnetic field, measurements are typically made relative to 1 picoTesla (pT). With this, the ac magnetic field can be expressed using Equation (1).

$$
\mathrm{dBpT}=20 \log \left(\frac{M}{1 \mathrm{pT}}\right)
$$

where $M$ is the ac magnetic field strength in $\mathrm{pT}$ and the output of the equation is the magnetic field strength in decibel pT. A magnetic field strength of $1 \mathrm{pT}$ corresponds to $0 \mathrm{dBpT}$, since the ratio inside the $\log$ operation would be 1 . Also, a change of $1 \mathrm{~dB}$ corresponds to a 12 percent change in the field strength. Emitted field strengths are typically measured at distances ranging from 0.25 to $3.0 \mathrm{~m}$, with the field strength measurement at $1.0 \mathrm{~m}$ being most commonly used. For spacecraft specifications, a maximum field strength at $1.0 \mathrm{~m}$ is usually specified. The dc magnetic fields can be nullified by arrangement of compensating permanent magnets at appropriate positions around the source of the field. The ac magnetic fields can be shielded with materials commonly referred to as "mu-metal" and "permalloy" which are alloys of iron and nickel. Mu-metals consist of an alloy with a large percentage nickel, and a comparatively small percentage iron. The opposite is true for permalloy materials, where the alloy is comprised mostly of iron. The term mu-metal originates from the desire for high magnetic permeability, 
which is represented by the Greek letter mu $(\mu)$. Magnetic field emissions from the ASRG originate from the linear alternator in the Stirling convertors. The permanent magnets contribute to both the dc and ac magnetic fields. The alternating electrical current flowing through the alternator windings also contribute to the ac magnetic field.

The first test to characterize Sunpower convertor dc and ac magnetic field emissions was performed by Rocketdyne at their Space Power Electronics Laboratory, in Canoga Park, California. In March 2006, a single ASC prototype (ASC-1 \#2) was tested in both the shielded and unshielded configuration. The dc and ac magnetic field emissions were measured in four different configurations: unshielded, mu-metal shield, permalloy shield, and mu-metal plus permalloy shield. The dc magnetic field was mapped $360^{\circ}$ around the convertor's horizontal plane while in the non-operating state at distances of 1.0 and $1.5 \mathrm{~m}$. The maximum de magnetic field was found to be located along the axis of the convertor when facing the pressure vessel end. The mu-metal shield alone reduced the dc magnetic field at $1.0 \mathrm{~m}$ by 17 percent. The permalloy shield was slightly more effective, and reduced the dc magnetic field at $1.0 \mathrm{~m}$ by 23 percent. Both shields together reduced the magnetic field by 68 percent. The ac magnetic field was also measured in each of the four shielding configurations, but with the convertor operating. The measurements were taken along the radial direction away from the convertor alternator at distances ranging from 0.5 to $2.0 \mathrm{~m}$ in $0.25 \mathrm{~m}$ increments. Similarly, the shields were effective at attenuating the ac magnetic field. The mumetal shield alone reduced the ac magnetic field at $1.0 \mathrm{~m}$ by 70 percent. The permalloy shield reduced the field by 77 percent. Together, both shields reduced the field by 83 percent. This test demonstrated that commercially available magnetic shielding materials were capable of significantly attenuating both the dc and ac magnetic field emissions. The test also revealed that the unshielded dc and ac magnetic field strengths at $1.0 \mathrm{~m}$ were the same. This suggested that the majority of the ac magnetic field was due to the motion of the permanent magnets themselves, rather than the current flowing through the alternator windings.

The test performed at Rocketdyne suggested further investigation was warranted to find methods of reducing magnetic field emissions. It was also desired to learn more about which component of the alternator was most responsible for the ac magnetic field emissions. In August 2006, an experiment was conducted for this purpose at GRC. Instead of an operating convertor, an ASC-1 research alternator was driven by a linear motor of a different design than the ASC. This configuration isolated the source of the magnetic fields (the alternator) so that measurements could be made on the alternator alone. Since in this configuration the linear motor was coupled to the research alternator, the motor had to be shielded to allow accurate measurements of the research alternator. The dc magnetic field measurements were taken at distances from flush with the alternator up to $10 \mathrm{~cm}$ away, and at various locations along the axis. Because of the available instrumentation, the dc magnetic field could not be measured at $1.0 \mathrm{~m}$. The ac magnetic field measurements were taken at various distances (including $1.0 \mathrm{~m}$ ) and axial locations. Despite the use of mu-metal shielding around the linear motor, it was found that the motor's ac magnetic field still dominated the emissions. The mu-metal shield was capable of attenuating the linear motor emissions by $15 \mathrm{~dB}$, or 82 percent. This is a typical shield effectiveness for a simple cylindrical shield, but further attenuation was desired to isolate research alternator emissions. However, because of apertures necessary for wiring and mechanical connections, a large enough portion of the motor's ac magnetic field was able to escape the shield to interfere with the desired measurements. After measuring the ac magnetic field of the shielded linear motor and research alternator pair, the research alternator was then mechanically disconnected from the linear motor. Measurements of the ac magnetic field were then taken while exciting the shielded motor alone at the same frequency and amplitude. The ac magnetic field strength at $1.0 \mathrm{~m}$ was indistinguishable from the field measured while coupled to the alternator. This result suggested that efforts to isolate magnetic field emissions from the alternator would not be possible in this configuration due to the interference introduced by the drive motor. With this, the only conclusion that could be drawn was that the ac magnetic field emission from the alternator was lower than that measured while driving it with the linear motor. While driving the research alternator with a shielded linear motor, the measured ac magnetic field at $1.0 \mathrm{~m}$ was approximately $10 \mathrm{dBpT}$ higher than the limit imposed by the ASRG system specification. However, the system specification applies to a dual-opposed 
pair of convertors, and references the geometric center of the two alternators. Since this test was conducted on a single alternator, the results may not correlate directly to the system specification.

After finding that motoring an alternator to measure ac magnetic field emissions was inconclusive, the decision was made to repeat measurements on a dual-opposed pair of ASC-1s. In June 2007 ASC-1 \#3 and \#4 were operated in the EMI laboratory at NASA GRC. In this configuration, a more insightful measurement could be made, since there now existed a geometric center, as referenced in the ASRG system specification for EMI. The dc magnetic field measurements were again taken, but only in close proximity to one of the alternators. The dc magnetic field was measured on the surface of ASC-1 \#3's alternator housing at 5 axial locations and 2 radial locations. As was true during the prior test, the dc magnetic field at $1.0 \mathrm{~m}$ could not be measured due to available instrumentation. The ac magnetic field was measured at distances ranging from 1.0 to $3.0 \mathrm{~m}$ in both radial and axial directions from the center of the convertor pair. The ac magnetic field strengths at $1.0 \mathrm{~m}$ in the radial and axial directions differed by only $1.3 \mathrm{~dB}$, suggesting either location was suitable for this particular measurement. The ac magnetic field measurements suggested that the emission from this particular test article was up to $11 \mathrm{dBpT}$ higher than the ASRG system specification. This result was in close agreement with that of the research alternator test described previously. Since the measured field emissions were higher than the ASRG system specification, efforts focused on exploring mitigation techniques.

In November 2007, GRC engineers developed a novel EMI mitigating technique referred to as a bucking coil, for which a patent is pending. This coil consists of several loops of magnet wire wound around the alternator housing and wired in series with the alternator output. The coil thus uses a portion of the convertor output to generate a magnetic field. The coil axis is oriented parallel to the convertor axis and in a direction such that the field produced by the current flowing through the coil opposes and nullifies that generated by the alternator magnets and windings. Before EMI testing, the effect of the bucking coil on convertor performance was quantified in the Stirling research laboratory at GRC. ASC-1 \#3 and \#4 were operated with and without the coils inserted into the convertor power output pathway. The net effect was a 3 to 5 percent drop in power, which was in agreement with predictions due to the added resistance introduced by the bucking coil. After demonstrating that the bucking coil did not adversely affect convertor performance, the units were then transported to the EMI laboratory (Fig. 5). The convertors were first operated at the same baseline conditions as the last EMI test, with the bucking coil bypassed. Magnetic field measurements were then taken with the bucking coil in the circuit. The

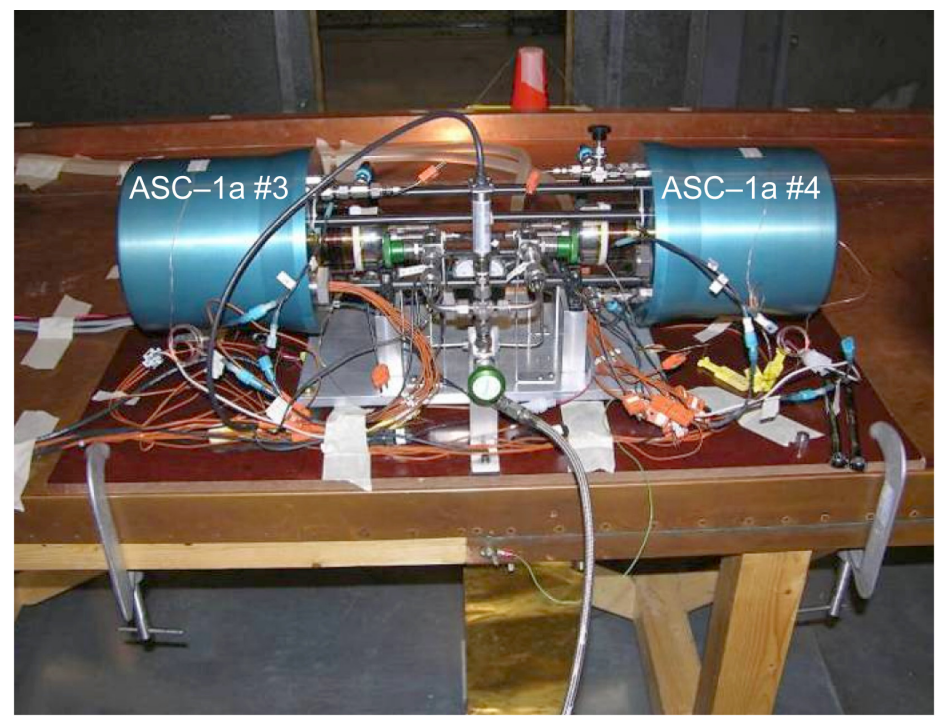

Figure 5.-ASC-1a \#3 and \#4 prepared for EMI testing with bucking coils around the alternator housings. 
number of turns in the bucking coil was also varied to determine the optimum configuration. The net effect of the optimum bucking coil configuration was a reduction in the ac magnetic field of $17.7 \mathrm{~dB}$, or 87 percent. This attenuated the ac magnetic field emissions to a level well below the limit imposed by the ASRG system specification.

In addition to EMI tests on ASC-1 prototypes, an EMI test was also conducted on the ASRG-EU, which comprises two ASC-E units. In March 2008, the EU generator underwent EMI testing at LM's facility in Valley Forge, Pennsylvania (Ref. 3). Both dc and ac magnetic fields were measured at $1.0 \mathrm{~m}$. The dc magnetic field was measured to be less than that of a GPHS-RTG. Specifications for certain missions requiring lower dc magnetic emissions can be met by the use of compensating permanent magnets. This technique has been used in the past to meet specifications for low frequency magnetometers, such as those on the Ulysses mission. The ac magnetic field measurements were similar in magnitude to those measured on the ASC -1 \#3 and \#4 convertors at NASA GRC.

The alternator housing of the ASCs is typically made from stainless steel or Inconel alloys. The idea was presented to further reduce magnetic field emissions by fabricating custom housings from a magnetic-shielding material. This is an attractive solution, since the housing would also serve the function of a magnetic shield, and avoid the extra mass associated with retrofitting an external shield. Housings made of Carpenter Technology's Perm-49 high magnetic permeability alloy were fabricated and installed on ASC-1 \#3 and \#4. EMI tests of these convertors with the Perm-49 housings began in June 2009, and results will be reported in future publications.

\section{Thermoacoustic Stirling Conversion}

The traditional method of free-piston Stirling conversion utilizes a displacer to shuttle working gas between the hot and cold ends of the machine. Since the displacer is exposed to the hot-end temperature, it must be made of a high temperature capable material, much like that of the heater head, which undergoes no motion but is exposed to the stress from working gas pressurization and thermal gradients. It is possible to eliminate the displacer, and thus eliminate all hot-end moving components, by implementing the thermoacoustic arrangement of Stirling conversion. Such an arrangement simplifies the design, since the only moving parts would be located in the relatively cool alternator. The thermoacoustic method accomplishes this by using high amplitude standing or traveling waves to send the working gas through the same pressure and volume oscillations as the displacer in a traditional machine. Thermoacoustic machines still make use of regenerators and hot and cold heat exchangers, but the gas is shuttled through these components by the acoustic wave. The temperature gradient across the hot and cold thermal reservoirs acts to supply energy to the acoustic wave, which may then act on a piston connected to a linear alternator to generate electricity.

In 2003, Northrop Grumman completed a contract during which a $100 \mathrm{~W}_{\mathrm{e}}$-class thermoacoustic convertor was designed and fabricated (Fig. 6). The convertor comprises a thermoacoustic Stirling heat engine (TASHE) coupled to a pair of linear alternators. The TASHE converts the heat into acoustic power, while the linear alternators accept this acoustic power and convert it to electricity. This unit demonstrated a peak conversion efficiency of 17.9 percent and a peak power output of $57 \mathrm{~W}_{\mathrm{e}}$. The Northrop Grumman thermoacoustic convertor was delivered to GRC in 2006, where it underwent checkout testing. The convertor was operated at GRC up to a hot-end temperature of $450{ }^{\circ} \mathrm{C}$, and demonstrated the ability to self start without the need for external excitation.

In 2008, Sunpower, Inc. produced a $100 \mathrm{~W}_{\mathrm{e}}$-class thermoacoustic Stirling convertor during a Phase II SBIR (Fig. 7). This design was similar in size, shape, and arrangement to the ASC that has been integrated into the ASRG-EU, except that it was modified to use an acoustic feedback circuit instead of a displacer. As such, the Sunpower design is coaxial, and thus the heat exchangers surround the thermal buffer tube. In contrast, the Northrop Grumman design was a loop arrangement, where the heat exchangers did not share a common axis. The Sunpower thermoacoustic convertor was designed for a radioisotope application and to accept heat from one GPHS module. The unit successfully operated as 


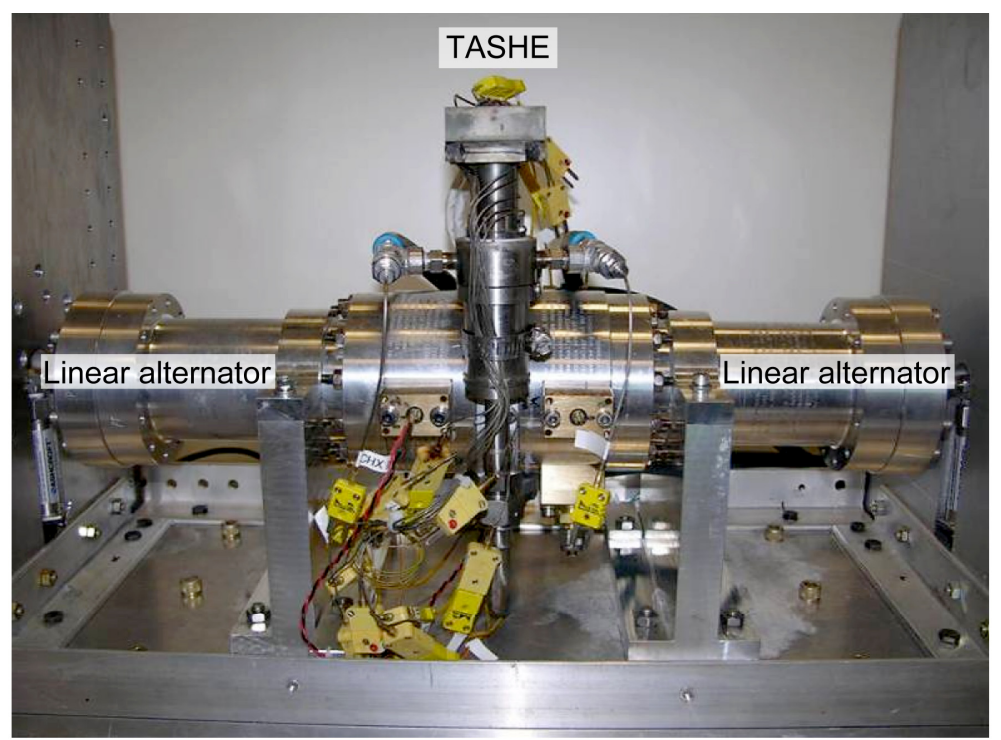

Figure 6.-Northrup Grumman thermoacoustic Stirling convertor configured for testing at NASA GRC. The centrally-located TASHE converts heat to acoustic power, which is then converted to electricity by the two linear alternators located at the outer ends.

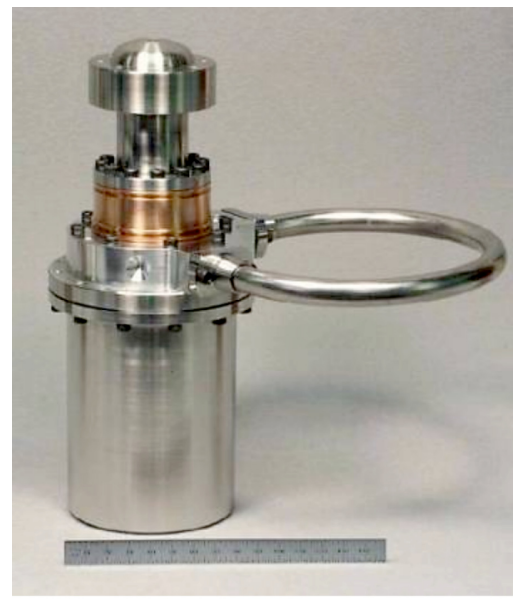

Figure 7.-Sunpower, Inc. thermoacoustic Stirling convertor. Image courtesy of Sunpower, Inc.

desired and produced $50 \mathrm{~W}_{\mathrm{e}}$. This activity demonstrated that an existing design could be modified to achieve thermoacoustic operation. The hardware was subsequently delivered to GRC in late 2008. A test station is being built at GRC that will be used to conduct operational research of this device.

Thermoacoustic Stirling technology offers an attractive option for power systems for long-lived Venus surface missions (Ref. 9). The Venus environment offers a significant challenge for the power system, as the conversion device must operate at a rejection temperature of up to $480^{\circ} \mathrm{C}$. To maintain desired efficiency, the hot-end operating temperature must increase accordingly, perhaps up to $1200^{\circ} \mathrm{C}$, which is a sizeable increase over the current state-of-the-art ASC operating at $850{ }^{\circ} \mathrm{C}$. Reference 9 describes in detail trade studies that were performed to investigate the use of a radioisotope-fueled, thermoacoustic Stirling power system that would provide power and cooling to a Venus lander. To advance this effort further, testing is planned to take place at NASA GRC on both the Sunpower and Northrop Grumman hardware. 


\section{Multiple-Cylinder Free Piston Stirling Conversion}

The majority of free-piston Stirling conversion technology development has been in the area of the "beta" configuration. The beta style comprises a lightweight displacer that oscillates between the hot and cold ends of the machine to generate the pressure wave (Fig. 8). This pressure wave then acts on a piston coupled to a linear alternator, which is coaxial with the displacer. This configuration utilizes two moving parts. The displacer does not have to maintain a high pressure seal across its body. Instead, it must only seal the pressure generated while shuttling the gas from one end to the other. The piston however must seal the working gas pressure from the aft end of the convertor, usually referred to as the bounce space. Since the piston is situated in the cold end of the convertor, there is little to no temperature gradient that must be accommodated.

Recently, new technology development efforts have focused on the alpha arrangement of pistons (Fig. 9). In this configuration, the double-acting pistons shuttle the gas between the hot and cold ends, in addition to absorbing mechanical energy from the pressure wave. The arrangement of cylinders is such that the expansion space above one piston is connected to the compression space of the adjacent piston through an interconnect passage that contains the regenerator. This arrangement has the advantage of eliminating one of the moving components in a given cylinder when compared to the beta arrangement. Alpha arrangements also offer a higher power density than that of the beta style, since the pistons are double-acting. One particular disadvantage to the alpha arrangement is the need for the piston seal to isolate across both a pressure gradient and a temperature gradient, which is not true for the beta arrangement. Because of this, the seal is usually placed at the bottom of the piston, near the cold end of the device. The hot-end would then have a relatively large clearance within the cylinder, introducing some additional dead volume.

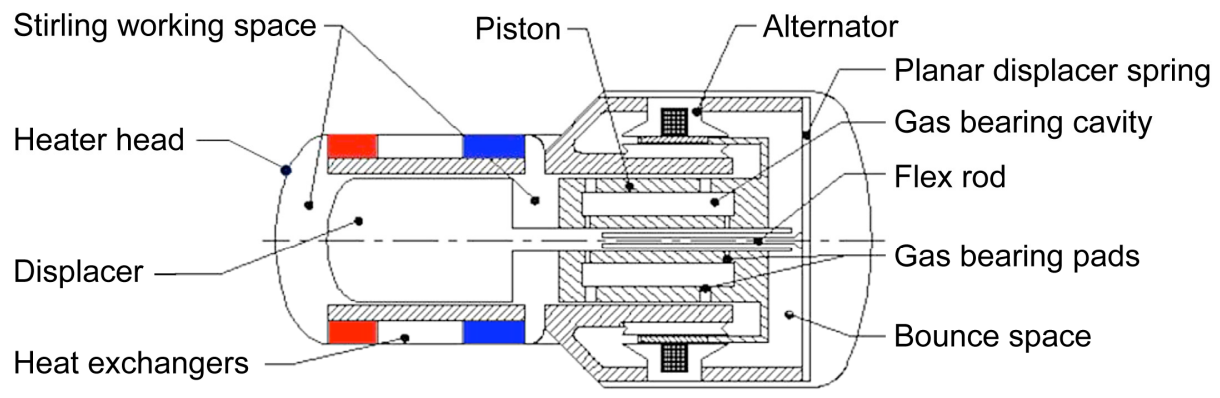

Figure 8.-Typical beta arrangement of a free-piston Stirling cycle machine. Image courtesy of Sunpower, Inc.

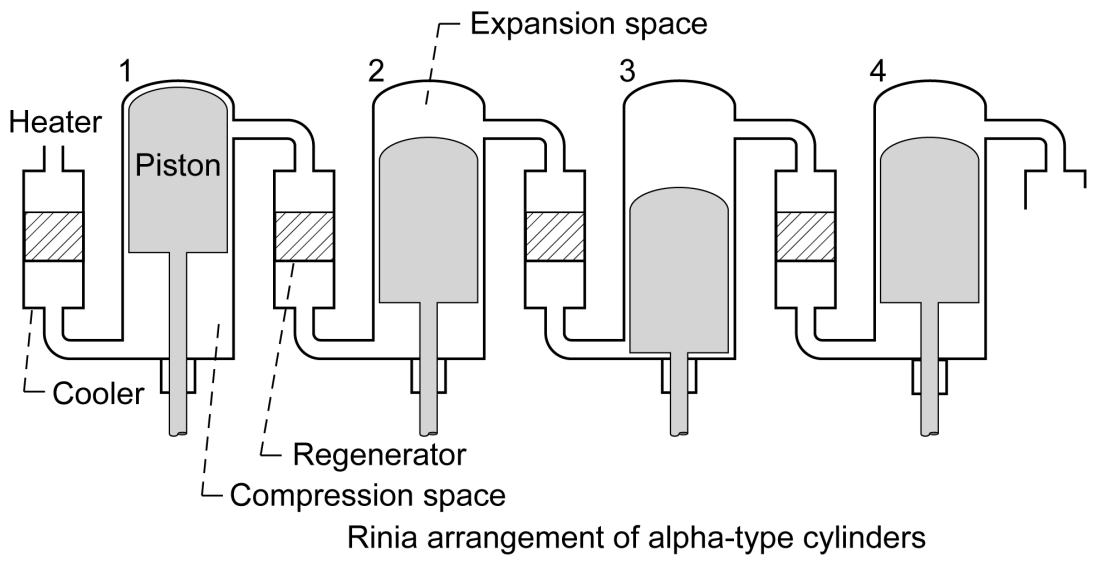

Figure 9.-Typical alpha arrangement of a Stirling cycle machine. 
The alpha arrangement has a long history of demonstrated feasibility in kinematic engines, meaning the motions of the pistons are connected via mechanical linkages. To enable long life however, the machine may make use of the free-piston configuration, meaning the output of each piston is isolated and connected to a linear alternator. This poses a significant technical challenge since the phasing of the piston motions cannot be controlled by mechanical means. Instead, the phasing must be controlled by the working gas dynamics, and electrical connection of the alternator outputs. For example, a $180^{\circ}$ piston phase difference can be realized by connecting the respective alternator outputs in anti-phase. Only recently has a free-piston Stirling alpha device been demonstrated (Ref. 6). The activity described by Reference 6 showed that even without physical connectivity between pistons, it was possible to maintain the desired phase angle between piston motions.

In 2005, an SBIR contract was awarded to Sunpower, Inc. to explore the design space for high power ( 5 to $25 \mathrm{~kW}_{\mathrm{e}}$ ) Stirling convertors (Ref. 5). This power level is representative of a fission surface power system, such as that which may be used for a permanent lunar base. Phase I of the SBIR evaluated several configurations for this power level, including single cylinder beta and multiple-cylinder alpha designs. The study suggested that specific power and efficiency could be improved over the baseline Component Test Power Convertor (CTPC), which was a $12.5 \mathrm{~kW}_{\mathrm{e}}$ convertor designed during the SP-100 project (Ref. 7). One of the configurations, a novel three-cylinder arrangement, was shown to be the best option. It was estimated that this design could improve specific power by 40 percent, and efficiency by 34 percent over that of the CTPC.

The SBIR then progressed to Phase II, which encompassed two goals. First a $30 \mathrm{~kW}_{\mathrm{e}}$ convertor assembly was designed, using two dual-opposed, three-cylinder alpha convertors, for a total of six cylinders each producing $5 \mathrm{~kW}_{\mathrm{e}}$. The Phase II effort also included a task to convert an existing fourcylinder alpha free-piston cooler into a convertor. This was undertaken to provide a demonstration device that could be used for research and thermodynamic code validation in support of the $30 \mathrm{~kW}_{\mathrm{e}}$ design. The use of multiple cylinders introduces other effects in cycle operation that are not present in beta convertors, such as seal loss through temperature gradient, cylinder interconnect dead volumes, and off-resonance pistons. The cooler was converted to operate as an engine by making small modifications, such as changing the hot-end material and installing an electric heat source. No other major modifications were required to permit operation of the device as an engine. The four-cylinder proof of concept convertor comprised four pistons each attached to a linear alternator. The inter-cycle connections were made via passages machined into the cap on the hot-end. This convertor successfully operated at Sunpower with no instability. It produced over $135 \mathrm{~W}$ at a hot-end temperature of $290^{\circ} \mathrm{C}$ and rejection temperature of $50{ }^{\circ} \mathrm{C}$, for a temperature ratio of approximately 1.74 . The results of this operation agreed closely with the predictions made by the thermodynamic models. Information gathered during the design and operation of this unit was used to guide the design of the $30 \mathrm{~kW}_{\mathrm{e}}$ convertor.

The four-cylinder demonstration convertor was then delivered to GRC (Fig. 10), where it underwent further testing. During the summer of 2008, the convertor completed both low and full temperature checkout, and performance mapping. Low temperature checkout was performed as the first step, during which the hot-end temperature was limited to $180^{\circ} \mathrm{C}$. Full temperature operation was performed at the design hot-end temperature of $300{ }^{\circ} \mathrm{C}$. Performance mapping was performed at various hot-end temperatures ranging from 180 to $300{ }^{\circ} \mathrm{C}$ and various piston amplitudes ranging from 75 percent design amplitude up to full design amplitude. The convertor produced $20 \mathrm{~W}_{\mathrm{e}}$ in the low temperature condition, and $115 \mathrm{~W}_{\mathrm{e}}$ in the full temperature condition (Fig. 11). Some test points could not be achieved due to offcenter oscillation of two pistons that was present when approaching the full design amplitude. This can be attributed to the fact that no centering mechanism was integrated into the design of the demonstration unit. The alternator outputs were connected to persuade the desired phasing between piston motions. Two of the alternators were connected in anti-phase, forcing those associated pistons to oscillate with a $180^{\circ}$ phase difference. The same was done with the other two alternators. The output of the two alternator pairs was then connected in parallel across a simple load resistor. No other methods were required to achieve 


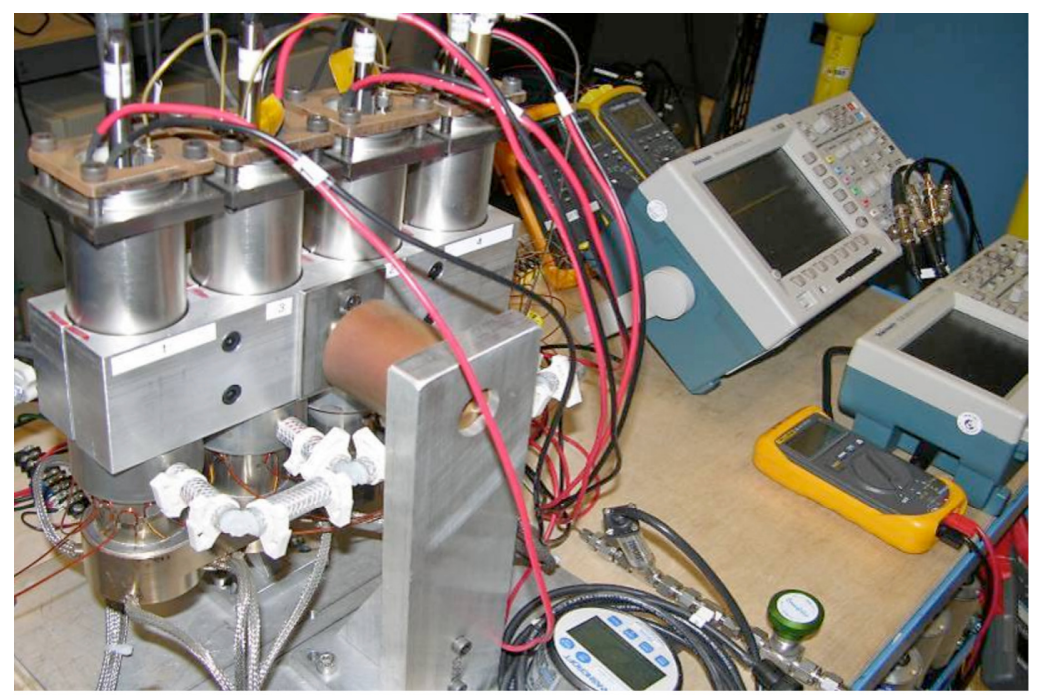

Figure 10.-Four-cylinder free piston demonstration unit set up at GRC.

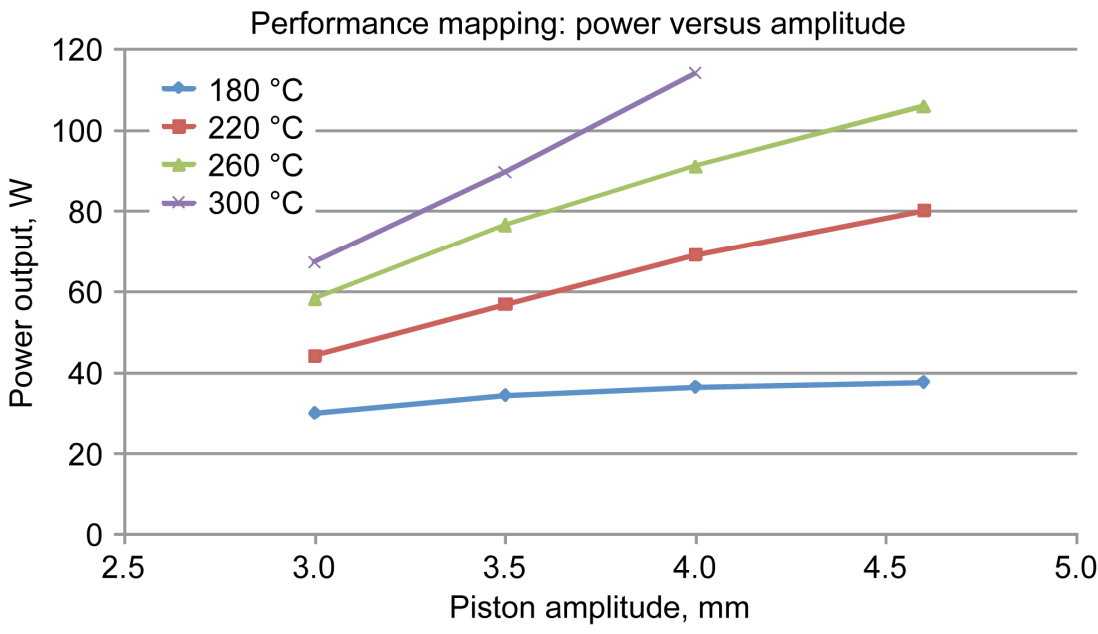

Figure 11.-Performance mapping results of the multi-cylinder demonstration unit at different hot-end temperatures and piston amplitudes.

the desired phase angle between piston motions. This is an accomplishment in the area of alpha freepiston Stirling conversion, since typically a more sophisticated control method is required that dithers the load to maintain stable operation. Furthermore, it demonstrated that the desired piston motions could be attained without physical linkages. When observed on an oscilloscope, the piston motions appeared $90^{\circ}$ apart, as desired, with no visible fluctuations.

\section{Conclusions}

Several recent Stirling conversion operational measurements and technology developments have been discussed. Activities related to operational measurements included acoustic emission characterization for health monitoring of several convertor life tests. Baseline acoustic signatures were characterized for several ASCs, and this information will be used throughout extended operation to track long term convertor performance. It was also found that while acoustic sensors could not detect the difference between operating and non-operating gas bearings, they could detect major changes such as piston to displacer 
contact or loosening of the planar spring fasteners. Also discussed were measurements of EMI emissions and the investigation of two mitigation techniques. During EMI tests on two ASC-1s the ac magnetic field could be attenuated to below the ASRG system specification with a simple bucking coil situated around the alternator. Custom alternator housings fabricated from high magnetic permeability material were also tested, and the results of this test are expected in the near future. Recent technology developments in the areas of thermoacoustic Stirling, and multiple-cylinder alpha arrangements were also discussed. Thermoacoustic Stirling conversion has been demonstrated in hardware on two separate occasions. Northrop Grumman and Sunpower Inc. each designed, fabricated, and tested their own $100 \mathrm{~W}_{\mathrm{e}}$-class devices, demonstrating Stirling conversion with no hot-end moving components. These devices were both delivered to GRC, where testing and research is scheduled to continue in the summer of 2009. Sunpower, Inc. and Global Cooling produced a four-cylinder alpha free-piston Stirling convertor prototype that was subsequently tested at GRC. The convertor produced over $100 \mathrm{~W}_{\mathrm{e}}$ at a hot-end temperature of $300^{\circ} \mathrm{C}$. This effort demonstrated that freepiston Stirling conversion could also be accomplished in the multiple-cylinder arrangement, which offers higher power density and specific power.

\section{References}

1. Schreiber, J.G., "Supporting Technology at GRC to Mitigate Risk as Stirling Power Conversion Transitions to Flight," $6^{\text {th }}$ International Energy Conversion Engineering Conference (IECEC), Cleveland, OH, 2008.

2. Wilson, K., "Sunpower Delivery of ASC-E Convertors and Progress Toward Flight," ${ }^{\text {th }}$ International Energy Conversion Engineering Conference (IECEC), Cleveland, OH, 2008.

3. Chan, J., "Development of Advanced Stirling Radioisotope Generator for Planetary Surface and Deep Space Missions," $6^{\text {th }}$ International Energy Conversion Engineering Conference (IECEC), Cleveland, $\mathrm{OH}, 2008$.

4. Lewandowski, E.J., "Extended Operation Testing of Stirling Convertors in Support of Stirling Radioisotope Power System Development," $6^{\text {th }}$ International Energy Conversion Engineering Conference (IECEC), Cleveland, OH, 2008.

5. Kim, S.Y., "Specific Power Estimations for Free-Piston Stirling Engines," $4^{\text {th }}$ International Energy Conversion Engineering Conference (IECEC), San Diego, CA, 2006.

6. White, M.A., "The Multi-Cylinder Free-Piston Stirling Engine - Taking Performance to a New Level," $3^{\text {rd }}$ International Energy Conversion Engineering Conference (IECEC), San Francisco, CA, 2005.

7. Jones, D., "Space Power Free-Piston Stirling Engine Scaling Study," NASA/CR-182218, 1989.

8. Petach, M., "Design and Testing of a thermal to Electric Power Convertor Based on Thermoacoustic Technology," $2^{\text {nd }}$ International Energy Conversion Engineering Conference (IECEC), Providence, RI, 2004.

9. Dyson, R., "Long-lived Venus Lander Conceptual Design: How to Keep it Cool," $7^{\text {th }}$ International Energy Conversion Engineering Conference (IECEC), Denver, Co, 2009. 


\begin{tabular}{|c|c|c|}
\hline \multicolumn{2}{|c|}{ REPORT DOCUMENTATION PAGE } & $\begin{array}{l}\text { Form Approved } \\
\text { OMB No. 0704-0188 }\end{array}$ \\
\hline \multicolumn{3}{|c|}{$\begin{array}{l}\text { The public reporting burden for this collection of information is estimated to average } 1 \text { hour per response, including the time for reviewing instructions, searching existing data sources, gathering and maintaining the } \\
\text { data needed, and completing and reviewing the collection of information. Send comments regarding this burden estimate or any other aspect of this collection of information, including suggestions for reducing this } \\
\text { burden, to Department of Defense, Washington Headquarters Services, Directorate for Information Operations and Reports ( } 0704-0188) \text {, } 1215 \text { Jefferson Davis Highway, Suite } 1224 \text {, Allington, VA } 22222-24302 \text {. } \\
\text { Respondents should be aware that notwithstanding any other provision of law, no person shall be subject to any penalty for failing to comply with a collection of information if it does not display a currently valid OMB } \\
\text { control number. } \\
\text { PLEASE DO NOT RETURN YOUR FORM TO THE ABOVE ADDRESS. }\end{array}$} \\
\hline $\begin{array}{l}\text { 1. REPORT DATE (DD-MM-YYYY) } \\
01-08-2010\end{array}$ & $\begin{array}{l}\text { 2. REPORT TYPE } \\
\text { Technical Memorandum }\end{array}$ & 3. DATES COVERED (From - To) \\
\hline \multirow{3}{*}{\multicolumn{2}{|c|}{$\begin{array}{l}\text { 4. TITLE AND SUBTITLE } \\
\text { Recent Stirling Conversion Technology Developments and Operatic } \\
\text { NASA Glenn Research Center }\end{array}$}} & 5a. CONTRACT NUMBER \\
\hline & & 5b. GRANT NUMBER \\
\hline & & 5c. PROGRAM ELEMENT NUMBER \\
\hline \multirow{3}{*}{\multicolumn{2}{|c|}{$\begin{array}{l}\text { 6. AUTHOR(S) } \\
\text { Oriti, Salvatore, M.; Schifer, Nicholas, A. }\end{array}$}} & 5d. PROJECT NUMBER \\
\hline & & 5e. TASK NUMBER \\
\hline & & $\begin{array}{l}\text { 5f. WORK UNIT NUMBER } \\
\text { WBS } 138494.04 .01 .01\end{array}$ \\
\hline \multicolumn{2}{|c|}{$\begin{array}{l}\text { 7. PERFORMING ORGANIZATION NAME(S) AND ADDRESS(ES) } \\
\text { National Aeronautics and Space Administration } \\
\text { John H. Glenn Research Center at Lewis Field } \\
\text { Cleveland, Ohio 44135-3191 }\end{array}$} & $\begin{array}{l}\text { 8. PERFORMING ORGANIZATION } \\
\text { REPORT NUMBER } \\
\text { E-17232 }\end{array}$ \\
\hline \multirow{2}{*}{\multicolumn{2}{|c|}{$\begin{array}{l}\text { 9. SPONSORING/MONITORING AGENCY NAME(S) AND ADDRESS(ES) } \\
\text { National Aeronautics and Space Administration } \\
\text { Washington, DC 20546-0001 }\end{array}$}} & $\begin{array}{l}\text { 10. SPONSORING/MONITOR'S } \\
\text { ACRONYM(S) } \\
\text { NASA }\end{array}$ \\
\hline & & $\begin{array}{l}\text { 11. SPONSORING/MONITORING } \\
\text { REPORT NUMBER } \\
\text { NASA/TM-2010-216245 }\end{array}$ \\
\hline \multicolumn{3}{|c|}{$\begin{array}{l}\text { 12. DISTRIBUTION/AVAILABILITY STATEMENT } \\
\text { Unclassified-Unlimited } \\
\text { Subject Category: } 20 \\
\text { Available electronically at http://gltrs.grc.nasa.gov } \\
\text { This publication is available from the NASA Center for AeroSpace Information, 443-757-5802 }\end{array}$} \\
\hline
\end{tabular}

\section{SUPPLEMENTARY NOTES}

\section{ABSTRACT}

In support of the Advanced Stirling Radioisotope Generator (ASRG) project and other potential applications, NASA Glenn Research Center (GRC) has initiated convertor technology development efforts in the areas of acoustic emission, electromagnetic field mitigation, thermoacoustic Stirling conversion, and multiple-cylinder alpha arrangements of Stirling machines. The acoustic emission measurement effort was developed as a health monitoring metric for several Stirling convertors undergoing life testing. While accelerometers have been used in the past to monitor dynamic signature, the acoustic sensors were chosen to monitor cycle events, such gas bearing operation. Several electromagnetic interference (EMI) experiments were performed on a pair of Advanced Stirling Convertors (ASC). These tests demonstrated that a simple bucking coil was capable of reducing the alternating current (ac) magnetic field below the ASRG system specification. The thermoacoustic Stirling concept eliminates the displacer typically found in Stirling machines by making use of the pressure oscillations of a traveling acoustic wave. A $100 \mathrm{~W}$-class thermoacoustic Stirling prototype manufactured by Northrop Grumman Space and Technology was received and tested. Another thermoacoustic prototype designed and fabricated by Sunpower, Inc., will be tested in the near future. A fourcylinder free piston alpha prototype convertor was received from Sunpower, Inc. and has been tested at GRC. This hardware was used as a proof of concept to validate thermodynamic models and demonstrate stable operation of multiple-cylinder free-piston Stirling conversion.

This paper will discuss each of these activities and the results they produced.

\section{SUBJECT TERMS}

Advanced Stirling radioisotope generator; Acoustic emission measurement; Stirling convertors

\begin{tabular}{|c|c|c|c|c|c|}
\hline \multicolumn{3}{|c|}{ 16. SECURITY CLASSIFICATION OF: } & \multirow{2}{*}{$\begin{array}{l}\text { 17. LIMITATION OF } \\
\text { ABSTRACT } \\
\text { UU }\end{array}$} & \multirow{2}{*}{$\begin{array}{l}\text { 18. NUMBER } \\
\text { OF } \\
\text { PAGES } \\
20\end{array}$} & \multirow{2}{*}{$\begin{array}{l}\text { 19a. NAME OF RESPONSIBLE PERSON } \\
\text { STI Help Desk (email:help@ } \text { sti.nasa.gov) } \\
\text { 19b. TELEPHONE NUMBER (include area code) } \\
\text { 443-757-5802 }\end{array}$} \\
\hline $\begin{array}{l}\text { a. REPORT } \\
\text { U }\end{array}$ & $\begin{array}{l}\text { b. ABSTRACT } \\
U\end{array}$ & $\begin{array}{l}\text { c. THIS } \\
\text { PAGE } \\
\text { U }\end{array}$ & & & \\
\hline
\end{tabular}



